\title{
Fracture properties of green mortars with recycled sand
}

\author{
Luciana Restuccia \\ Politecnico di Torino, Turin, Italy \\ luciana.restuccia@polito.it, bttps://orcid.org/0000-0002-6999-0466
}

\begin{abstract}
Urbanisation is consuming huge amounts of sand, being the basic element of concrete and glass, two of the most popular construction materials. Unfortunately, sand mining is causing environmental damage and drastically reducing the amount of raw resources. The main topic of this research is to investigate the use of Construction and Demolition waste finer fraction namely recycled sand - to totally replace the standard one into traditional mortars. From the analysis of the mechanical characterization of specimens, it is possible to state that recycled sand could represent a new resource for green and sustainable mortars.
\end{abstract}

KEYwORDS. Mortar; Superplasticizer; Recycled Sand; CDW; Fracture properties.

\section{OPEN ACCESS}

Citation: Restuccia, L., Fracture properties of green mortars with recycled sand, Frattura ed Integrità Strutturale, 49 (2019) 676-689.

Received: 15.04 .2019

Accepted: 31.05.2019

Published: 01.07.2019

Copyright: (C) 2019 This is an open access article under the terms of the CC-BY 4.0, which permits unrestricted use, distribution, and reproduction in any medium, provided the original author and source are credited.

\section{INTRODUCTION}

A ggregates like sand and gravel represent the largest volume of solid material globally extracted. The amount of their use is constantly increasing, due to the global economic growth: every year, between 47 and 59 billion tons of aggregates is mined [1], since they are used in a wide range of sectors.

However, their largest use is in construction sector, because they are the main elements for the concrete production: for each ton of cement, building industry needs about six to seven times more tons of sand and gravel [2]. The problem becomes even environmental: $1 \mathrm{~kg}$ of cement produced gives an equivalent of 0.9 carbon dioxide tons in atmosphere. There are some ways for reducing the extraction and the consumption of sand, for example by including quarry dust [3-5] or fly ash [6,7] in substitution of sand.

Furthermore, materials by CDW could be used to avoid the use of aggregates. Nowadays, however, the major CDW use is for road construction (unbound sub-base and base layers, bituminous surface pavements), due to their uncertain quality [8]. Moreover, as regard to the fine fraction (sand), the general opinion is that it has limited application due to its negative effect on concrete properties [9]. In fact, the fine fraction of CDW strongly influence the rheological properties and workability of concretes [10], for its intrinsic properties and amount.

Dapena et al. [11] studied the mechanical behaviour of mortars by using Recycled Sand (RS) contents of $0 \%, 5 \%, 10 \%$, $15 \%, 20 \%$ and $50 \%$ by weight. The results showed that the use of up to $20 \%$ recycled aggregates caused a drop in the compressive and flexural strength. Braga et al. [12] showed that it is feasible to use up to $15 \%$ of fine concrete recycled aggregates (maximum amount tested) in mortar production. In fact, this percentage caused an improvement in the reference mortar properties. Zhao [13] analysed the influence of recycled sand saturation state on mortar properties, then evaluated 
the influence of either replacement percentage or replacement fraction of natural sand by recycled sand, by volume (slump, compressive and flexural strength, ITZ microstructure). The results showed that the slump of mortars containing dried recycled sand is always larger than the one of the mortars with saturated one (pre-saturated 24h before the mix), because water is not immediately adsorbed into the cement paste at the initial time [13]. Moreover, results also showed that the compressive strength of mortars with recycled sand is always lower than the reference mortar, with a quasi-linear decrease as the replacement percentage of recycled sand increases [13].

Two parameters to be taken into account for the realisation of construction materials with fine recycled sand are the amount of fine content, which influence its workability, water absorption and shrinkage [14-16] and the amount of superplasticizer, which prevents the flocculation of cement particles when recycled aggregates are used [17].

Miranda and Selmo [18] analysed the effect of materials finer than $75 \mu \mathrm{m}$ on mortar properties and they found that the distribution of the pore sizes generated by the presence of fines in the mixtures had a higher effect on drying shrinkage than those of the porosity introduced by the effective water/cement ratio itself.

Bravo et al. [19] studied the superplasticizer efficiency on the mechanical properties of recycled aggregates concrete founding that incorporation of $1 \%$ of polycarboxylic-based superplasticizers has been beneficial in all percentages used, but the extent of its effect was dependent on the aggregate composition. Cartuxo et al. [20] studied the rheological behaviour of concrete made with fine recycled concrete aggregates founding that the addition of high-performance superplasticizers (a fixed proportion of $1 \%$ of cement mass was used) can offset the negative effects of fine recycled aggregates concrete introduction in mixtures. The fine fraction of CDW can be used like a filler to produce engineered cement composites [21] or for preparing self-compacting concrete mixes, but $20 \%$ is the maximum replacement level [22] while its use only as a replacement of standard sand is almost impossible.

Therefore, the objective of this study is the utilisation of fine CDW (also called recycled sand) to reproduce the granulometric distribution of the standard one, to completely replace it in traditional mortar.

The authors, in their first investigation about recycled sand in mortars [23], have analysed its effect in different compositions without additions of superplasticizer. As expected, the large water demand has been the main problem and it has not been possible to replace over $50 \%$ of standard sand. For this reason, superplasticizer has been used to obtain a workable mixture: it was added with respect to the weight of cement, nevertheless the problem of workability has not been resolved. On the contrary, the authors achieved quite satisfactory results through the recycled sand washing process, which allows the elimination of finer particles of poor quality, by using water and sieves, limiting the problem of water absorption [24]. Another important result obtained was related to the percentage of superplasticizer, added on the basis of the weight of the recycled sand (the quantity usually varies according to the weight of the cement): this solution was suitable to go beyond the complexity of the exact prediction of required $\mathrm{w} / \mathrm{c}$ ratio for attaining the desirable mechanical performances.

In this research paper, the prosecution of the previous research [24] has been carried out: the percentages of substitution reach up to $100 \%$ to promote the sustainable use of recycled sand into traditional mortars. Moreover, the recycled sandbased composites have been characterized not only from a mechanical point of view, but they were also analysed considering the fracture behaviour and the variation in the phase compositions via X-ray diffraction analysis.

\section{MATERIAL AND METHODS}

\section{Materials and specimen's preparation}

ૉ $\mathrm{n}$ this work, recycled sand provided by Cavit S.p.A. has been used (Fig. 1). It is characterized by particle size less than $8 \mathrm{~mm}$, with a plasticity index and a liquid limit equal to 0.9 and 26.4 respectively (Atterberg Limits). In the Declaration of conformity of this product (CE Marking) drawn up by the Cavit S.p.A., according to UNI EN 13242:2013 "Aggregates for unbound and hydraulically bound materials for use in civil engineering work and road construction", the parameters are indicated in Tab. 1 below:

\begin{tabular}{ll}
\hline Density of particle & $2.5 \mathrm{Mg} / \mathrm{m}^{3}$ \\
& \\
Fine granular content & $S E \geq 28$ \\
Fine granular quality & $M B 1.25$ \\
Water Absorption & $4 \leq W A_{24} \leq 6$ \\
\hline
\end{tabular}

Table 1: “Recycled 0-8” (UNI EN 13242). 


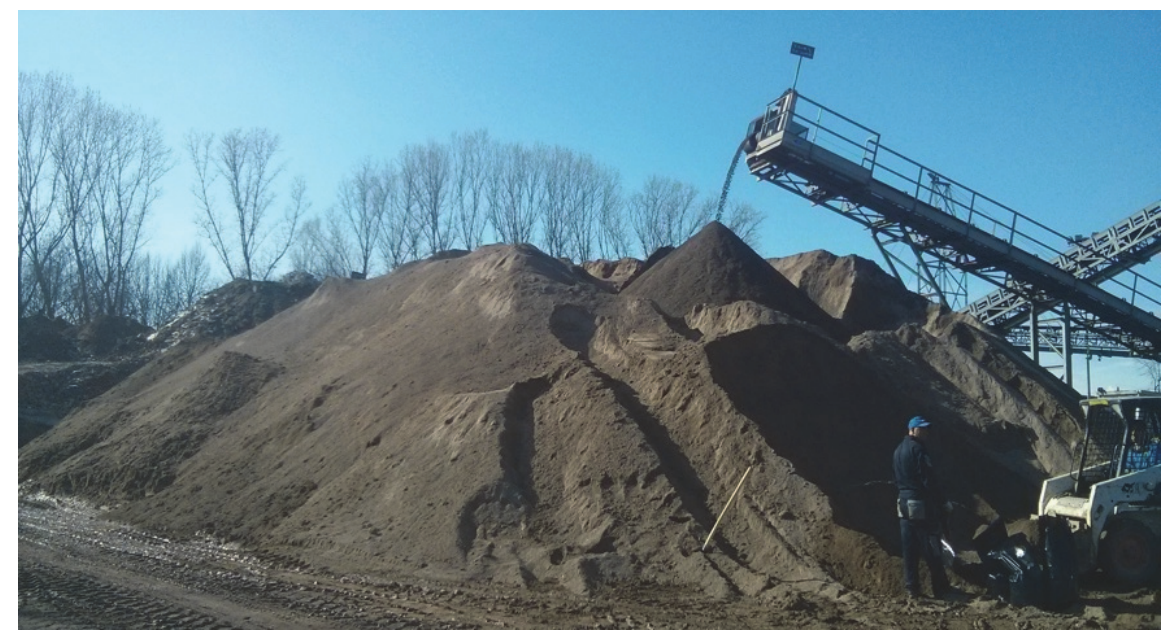

Figure 1: CDW waste treatment plant, Cavit S.p.A., La Loggia- Turin.

The determination of particle size distribution of SS and RSw has been realized through dry sieve, according to UNI EN 933-1 (Fig. 2).

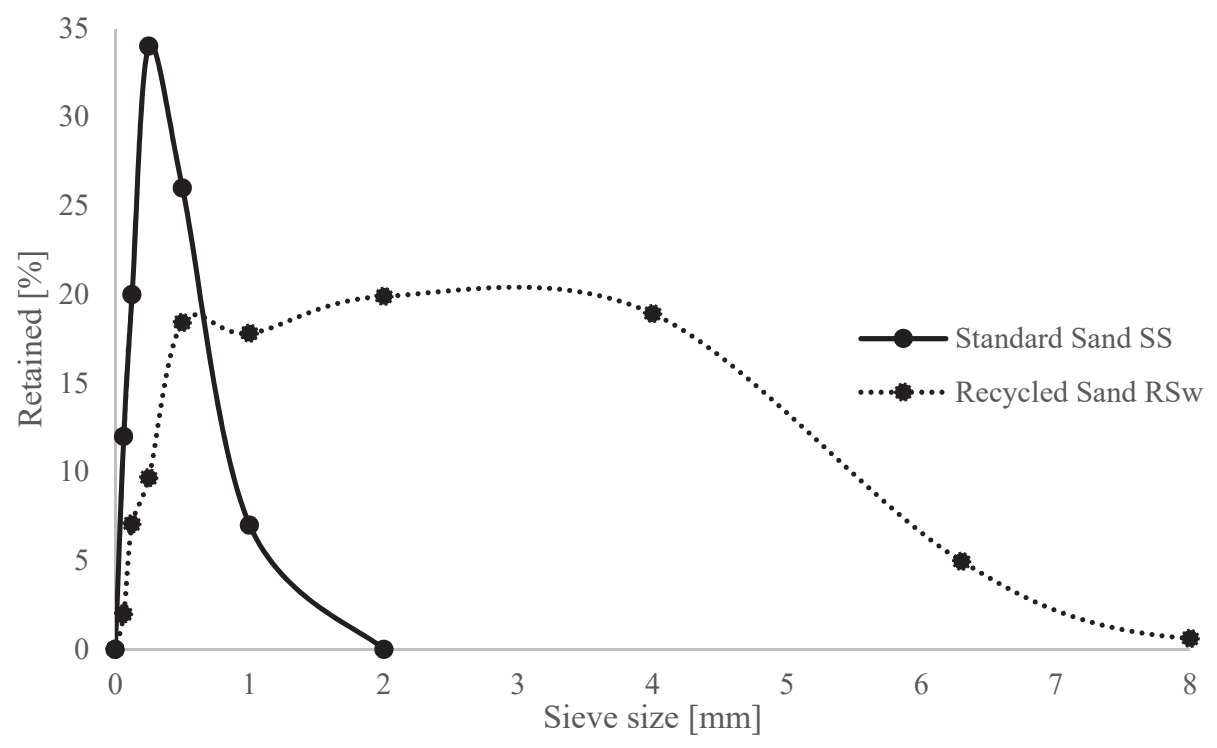

Figure 2: Particle size distribution of Standard Sand (SS) and Recycled Washed Sand (RSw).

The retained RSw residue at each sieve (0.08; 0.16; $0.50 ; 1.00$ and $1.60 \mathrm{~mm})$ has been analysed by means of X-Ray Diffraction (XRD). This kind of analysis, even if does not provide direct information on the sample chemical composition, allows defining and quantifying the crystalline phases present in the first $20 \mu \mathrm{m}$ of the sample surface. XRD patterns has been recorded with a Pan Analytical X'Pert Pro diffractometer, between $5^{\circ}$ and $70^{\circ}$ in $2 \theta$, with a step width of $0.026^{\circ}$ and $1 \mathrm{~s}$ data collection per step ( $\mathrm{CuK} \alpha$ radiation and graphite secondary monochrome). Moreover, a surface morphology study by FESEM Zeiss Supra-40 (Field Emission Scanning Electron Microscopy) has been carried out to identify the microstructure and the particle size of RSw grains.

Mortars with standard sand have been prepared as references and, according to the previous studies [24], experimental recycled mortars have been casted by using recycled washed sand $(\mathrm{RSw})$, as washing process helps to eliminate the finer particles that affect workability and water absorption. 
Sand packets have been realized through remixing of each granular fraction of standard sand SS with the corresponding granular fraction of recycled washed sand RSw, using four different percentages $(25 \%, 50 \%, 75 \%$ and $100 \%)$ of replacement. In Tab. 3, the four different mix compositions with the specific amounts of both of them are reported:

\begin{tabular}{cccc}
\hline $\begin{array}{c}\text { Square mesh size } \\
{[\mathrm{mm}]}\end{array}$ & $\begin{array}{c}\text { Cumulative retained } \\
{[\%]}\end{array}$ & $\begin{array}{c}\text { Retained } \\
{[\%]}\end{array}$ & $\begin{array}{c}\text { Retained mass } \\
{[\mathrm{g}]}\end{array}$ \\
2.00 & 0 & 0 & 0 \\
1.60 & 7 & 7 & 94.5 \\
1.00 & 33 & 26 & 351 \\
0.50 & 67 & 34 & 459 \\
0.16 & 87 & 20 & 270 \\
0.08 & 99 & 12 & 162 \\
Filler & 100 & 1 & 13.5 \\
\hline
\end{tabular}

Table 2: CEN Standard Sand - Granular fractions.

\begin{tabular}{ccccccccc}
\hline & \multicolumn{2}{c}{$25 \%$} & \multicolumn{2}{c}{$50 \%$} & \multicolumn{2}{c}{$75 \%$} & \multicolumn{2}{c}{$100 \%$} \\
Size & SS & RSw & SS & RSw & SS & RSw & SS & RSw \\
{$[\mathrm{mm}]$} & {$[\mathrm{g}]$} & {$[\mathrm{g}]$} & {$[\mathrm{g}]$} & {$[\mathrm{g}]$} & {$[\mathrm{g}]$} & {$[\mathrm{g}]$} & {$[\mathrm{g}]$} & {$[\mathrm{g}]$} \\
\hline 1.60 & 70.9 & 23.6 & 47.25 & 47.25 & 23.6 & 70.9 & 0 & 94.5 \\
1.00 & 263.3 & 87.8 & 175.5 & 175.5 & 87.8 & 263.3 & 0 & 351 \\
0.50 & 344.25 & 114.75 & 229.5 & 229.5 & 114.75 & 344.25 & 0 & 459 \\
0.16 & 202.5 & 67.5 & 135 & 135 & 67.5 & 202.5 & 0 & 270 \\
0.08 & 121.5 & 40.5 & 81 & 81 & 40.5 & 121.5 & 0 & 162 \\
$<0.08$ & 10.1 & 3.4 & 6.8 & 6.8 & 3.4 & 10.1 & 0 & 13.5 \\
\hline
\end{tabular}

Table 3: Mix compositions of sand packets with Recycled Washed Sand RSw.

The specimens have been manufactured in accordance with UNI EN 196-1:2005 (standard procedure). After 24 hours from the moulding procedure, all the specimens have been cured in water for 7 days. In Tab. 4 , the main characteristics of the specimen series produced are reported. It is important to underline that, after washing process, it was very hard to collect a sufficient quantity of $<0.08 \mathrm{~mm}$ fraction. For this reason, a calcium carbonate filler named VG1 has been used for replacing the filler fraction (in total $13.5 \mathrm{~g}$ as shown in Tab. 2); this substitution does not involve any substantial change, as it only accounts for $1 \%$ of the total amount of sand used.

In order to achieve an optimal mix-design, two parameters have been modulated: the amount of superplasticizer (SP1, acrylic polymer of MAPEI Dynamon SP system) and water/cement ratio. In Tab. 4, the mix-design summary for each composition: the strategy adopted is to gradually decrease both the amount of superplasticizer and the water/cement ratio, in order to obtain mortars with better mechanical performances. It is important to specify that for only standard sand mortar (M-SS), the SP1 has been added with respect to the weight of cement, while for the other compositions it has been varied according to the quantity of recycled washed sand RSw. 


\begin{tabular}{|c|c|c|c|c|c|c|c|c|c|}
\hline \multirow[t]{2}{*}{ \#SERIES } & \multirow{2}{*}{$\begin{array}{l}\text { ID } \\
\text { SPECIMEN }\end{array}$} & \multirow{2}{*}{$\begin{array}{l}\mathrm{w} / \mathrm{c} \\
{[-]}\end{array}$} & \multirow{2}{*}{$\begin{array}{c}\text { Cement } \\
{[\mathrm{g}]}\end{array}$} & \multirow{2}{*}{$\begin{array}{c}\text { Water } \\
{[\mathrm{g}]}\end{array}$} & \multicolumn{2}{|c|}{$\begin{array}{l}\text { Composition } \\
\text { Sand }[g]\end{array}$} & \multirow{2}{*}{$\begin{array}{l}\text { SP1 } \\
{[\%]}\end{array}$} & \multirow{2}{*}{$\begin{array}{l}\text { SP1 } \\
{[\mathrm{g}]}\end{array}$} & \multirow{2}{*}{$\begin{array}{c}\text { VG1 } \\
{[\mathrm{g}]}\end{array}$} \\
\hline & & & & & SS & RSw & & & \\
\hline \multirow{5}{*}{1} & M-SS & 0.5 & 450 & 225 & 1350 & 0 & 0 & 0 & 0 \\
\hline & M-RSw_25\% & 0.5 & 450 & 225 & 1002.4 & 334.1 & $1^{*}$ & $3.34^{*}$ & 13.5 \\
\hline & $\mathrm{M}-\mathrm{RS} \mathrm{w} \_50 \%$ & 0.5 & 450 & 225 & 668.2 & 668.2 & $1 *$ & $6.68^{*}$ & 13.5 \\
\hline & M-RSw_75\% & 0.5 & 450 & 225 & 334.1 & 1002.4 & $1 *$ & $10.24 *$ & 13.5 \\
\hline & M-RSw_100\% & 0.5 & 450 & 225 & 0 & 1336.5 & $1 *$ & $13.36^{*}$ & 13.5 \\
\hline \multirow{5}{*}{2} & M-SS & 0.5 & 450 & 225 & 1350 & 0 & 0 & 0 & 0 \\
\hline & $\mathrm{M}-\mathrm{RS} \mathrm{w} \_25 \%$ & 0.5 & 450 & 225 & 1002.4 & 334.1 & $0.75^{*}$ & $2.50^{*}$ & 13.5 \\
\hline & M-RSw_50\% & 0.5 & 450 & 225 & 668.2 & 668.2 & $0.75^{*}$ & $5.02^{*}$ & 13.5 \\
\hline & M-RSw_75\% & 0.5 & 450 & 225 & 334.1 & 1002.4 & $0.75^{*}$ & $7.51 *$ & 13.5 \\
\hline & M-RSw_100\% & 0.5 & 450 & 225 & 0 & 1336.5 & $0.75^{*}$ & $10.02^{*}$ & 13.5 \\
\hline \multirow{5}{*}{3} & M-SS & 0.45 & 450 & 202.5 & 1350 & 0 & 1 & 4.50 & 0 \\
\hline & $\mathrm{M}-\mathrm{RS} \mathrm{w} \_25 \%$ & 0.45 & 450 & 202.5 & 1002.4 & 334.1 & $1 *$ & $3.34 *$ & 13.5 \\
\hline & $\mathrm{M}-\mathrm{RS} \mathrm{w} \_50 \%$ & 0.45 & 450 & 202.5 & 668.2 & 668.2 & $1 *$ & $6.68^{*}$ & 13.5 \\
\hline & M-RSw_75\% & 0.45 & 450 & 202.5 & 334.1 & 1002.4 & $1^{*}$ & $10.24^{*}$ & 13.5 \\
\hline & M-RSw_100\% & 0.45 & 450 & 202.5 & 0 & 1336.5 & $1 *$ & $13.36^{*}$ & 13.5 \\
\hline \multirow{2}{*}{4} & M-SS & 0.40 & 450 & 180 & 1350 & 0 & 1 & 4.50 & 0 \\
\hline & M-RSw_100\% & 0.40 & 450 & 180 & 0 & 1336.5 & $1 *$ & $13.36^{*}$ & 13.5 \\
\hline
\end{tabular}

Table 4: Series of experimental mortars.

\begin{tabular}{lccc}
\hline ID SPECIMEN & $\begin{array}{c}\text { RSw } \\
{[\mathrm{g}]}\end{array}$ & $\begin{array}{c}\mathrm{SP} 1-0.75 \% \\
{[\mathrm{~g}]}\end{array}$ & $\begin{array}{c}\mathrm{SP} 1-1 \% \\
{[\mathrm{~g}]}\end{array}$ \\
M-RSw_25\% & 334.1 & 2.50 & 3.34 \\
M-RSw_50\% & 668.2 & 5.02 & 6.68 \\
M-RSw_75\% & 1002.4 & 7.51 & 10.24 \\
M-RSw_100\% & 1336.5 & 10.02 & 13.36 \\
\hline
\end{tabular}

Table 5: Mix-design of superplasticizer for each composition.

\section{THEORY AND TEST METHODS}

7 he classical Linear Elastic Fracture Mechanics (LEFM) theory is inadequate for cement-based materials [25], due to the development of a relatively large Fracture Process Zone (FPZ), which undergoes progressive softening damage due to mechanisms such as micro-cracking, crack branching, crack-deviation. One method developed to account for the FPZ in cement-based materials is the Two-Parameters Fracture Method [26], used in this research to understand the fracture process of mortars. The experimental determination of the Young's modulus E, the Fracture toughness KIC and the Fracture energy GF has been carried out by the evaluation of Load-CMOD curve for each specimen, during the threepoint bending tests, as indicated in RILEM TC 89- FMT METHODS [27].

The Young's modulus E for the different mixes has been calculated by the following equation:

$$
E=\frac{6 l a_{0} V_{1}(\alpha)}{C_{i} d^{2} b} \quad\left[N m^{-2}\right]
$$

in which $C_{i}$ is the initial compliance of the load-CMOD curve [m N $\left.\mathrm{N}^{-1}\right]$ and $\mathrm{V}_{1}(\alpha)$ is equal to: 


$$
V_{1}(\alpha)=0.76-2.28 \alpha+3.87 \alpha^{2}-2.04 \alpha^{3}+\frac{0.66}{(1-\alpha)^{2}}
$$

where $\alpha=\left(a_{0}+\mathrm{HO}\right) /(d+\mathrm{HO})$, and $l, \mathrm{a}_{0}, \mathrm{HO}, d$ and $b$ are those indicated in Fig. 3:
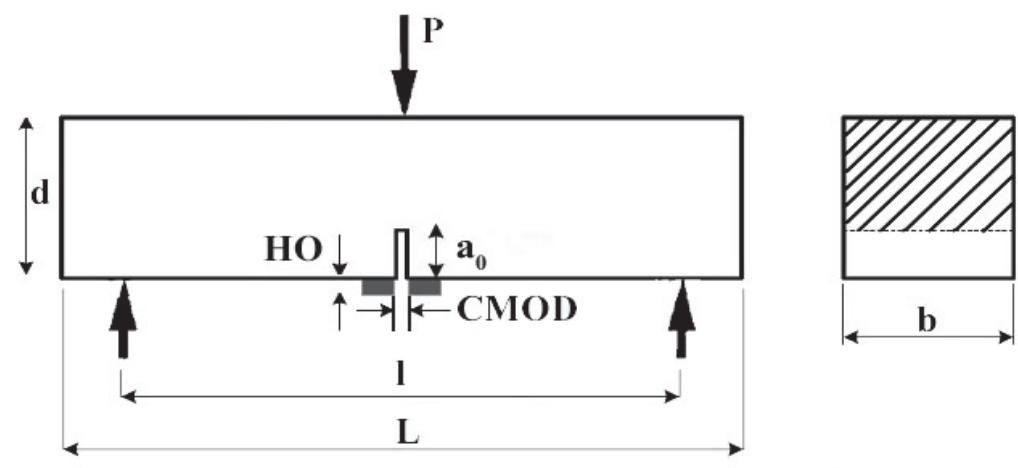

Figure 3: Testing configuration and geometry of specimen [27].

The critical stress intensity factor, $K_{I C}$, represents the resistance opposed by the material for a crack extension in plane strain condition for stress state near the crack tip, with limited plastic deformation.

In case of Mode I, the stress intensity factor $K_{I C}$ can be expressed as:

$$
K_{I C}=\frac{3\left(P_{\max }+0.5 W\right) l \sqrt{\pi a}}{2 d^{2} b} F(\alpha) \quad\left[N m^{-\frac{3}{2}}\right]
$$

where:

$$
F(\alpha)=\frac{1.99-\alpha(1-\alpha)\left(2.15-3.93 \alpha+2.7 \alpha^{2}\right)}{\sqrt{\pi}(1+2 \alpha)(1-3 \alpha)^{\frac{3}{2}}}
$$

and $\alpha=\mathrm{a} / \mathrm{d}, \mathrm{P}_{\max }=$ maximum load $[\mathrm{N}], 1, \mathrm{~d}$ and $\mathrm{b}$ are the span, depth and width, respectively [27]. After the determination of $K_{I C}$, the fracture energy, $G_{F}$, has been evaluated according RILEM TC50-FMC [21] as:

$$
G_{F}=\frac{W_{0}-m g \delta_{0}}{A_{\text {lig }}} \quad\left[\frac{N}{m}\right]
$$
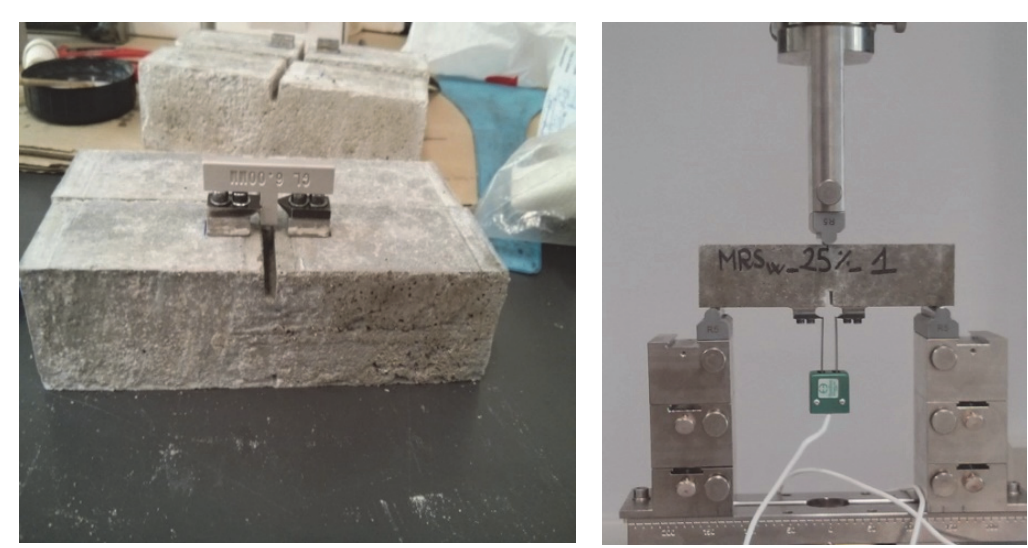

Figure 4: Set up and test of experimental mortars: three-point bending test. 
To evaluate the fracture properties for the different mixes, standard three-point bending (TPB) tests have been performed according to RILEM Recommendations [27,28].

The specimens had dimension of 160x40x40 mm, with a span/depth ratio equal to 4 and a notch/depth ratio equal to $1 / 3$. A single column displacement-controlled testing machine Zwick Line-Z050, with load cell of $50 \mathrm{kN}$ was used with a crosshead speed of $0.01 \mathrm{~mm} / \mathrm{min}$. Crack Mouth Opening Displacement (CMOD) has been controlled by using a clip-ongauge, placed across the notch and held in position by two steel knife-edges glued to the specimen (Fig. 4).

After flexural testing, each halves of the broken prism have been subjected to compression test by using an MTS servohydraulic machine (a modified Zwick machine), by loading its side faces through auxiliary plates of tungsten carbide of thickness $10 \mathrm{~mm}$ and surface $(40 \times 40 \mathrm{~mm})$. The tests have been performed with $0.05 \mathrm{~mm} / \mathrm{s}$ test speed (Fig. 5).

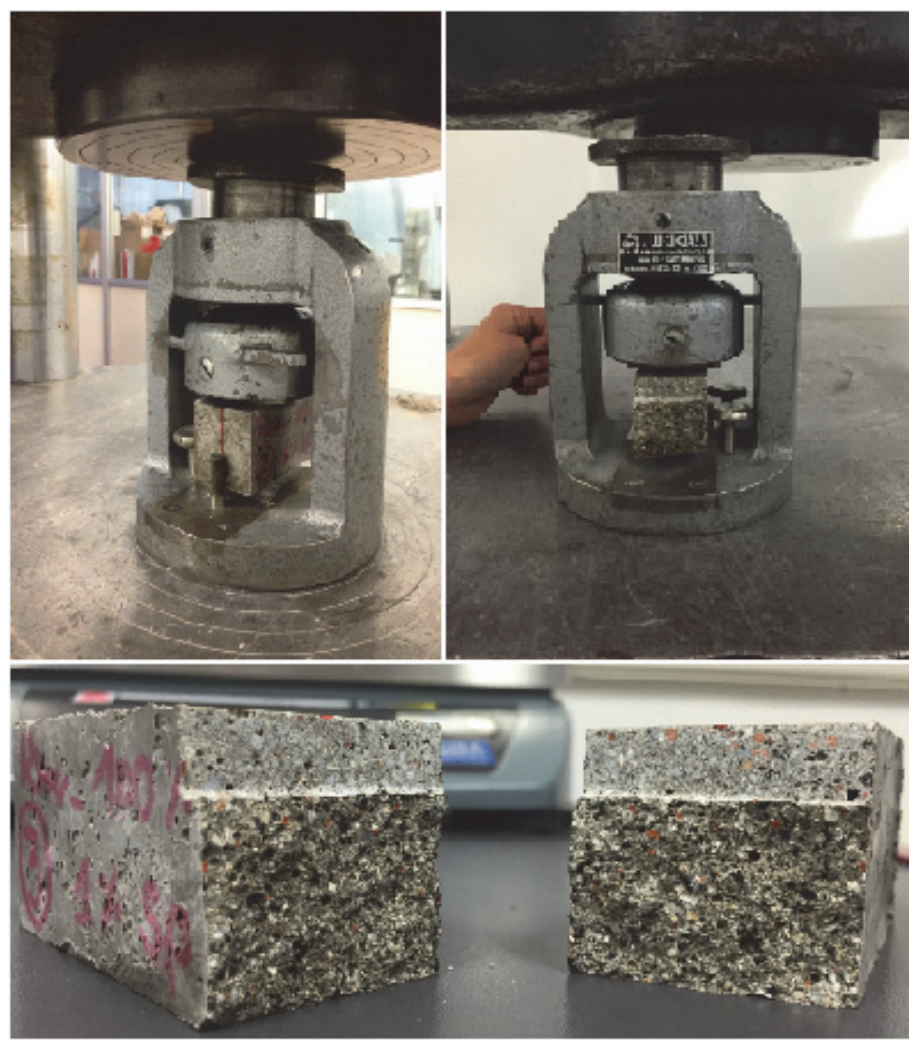

Figure 5: Set up and test of experimental mortars: compression test.

\section{RESULTS AND DISCUSSION}

\section{Results by XRD and FESEM analysis}

X

RD patterns of RSw showed the presence in all the samples of calcite (JCPDS card \#05-0586) and quartz (JCPDS card \#46-1045) as major constituents. Paragonite (a sodium aluminum silicate hydroxide, JCPDS card \#24-1047), phlogopite (a potassium magnesium aluminum silicate hydroxide, JCPDS card \#10-0493) and clinochlore (a magnesium aluminum iron silicate hydroxide, JCPDS card \#07-0078) were secondary phases. Gismondine (a calcium aluminum silicate hydrate, JCPDS card n³9-1373), probably due to hydrated cement residues, was found as traces (Fig. 6). Paragonite and clinochlore came from the aggregate fraction of former concrete, while calcite could have different origins: from aggregates, as cement filler, and from concrete degradation process (carbonation). Field Emission Scanning Electron Microscopy analysis (FESEM) were carried out for observing the shape of different fraction and for evaluating the capability of these recycled washed grains to ensure a good adherence to the cement paste. Generally, it seems that the smaller fraction has a sharpener shape $(0.08$ and $0.16 \mathrm{~mm})$, which could ensure a better adhesion with the cement matrix (Fig. 7). The larger grains $(\geq 1.00 \mathrm{~mm}$ ) instead have a more rounded form (Fig. 8). 
$\mathrm{C}=$ calcite, $\mathrm{Cl}=$ clinochlore, $\mathrm{Pa}=$ paragonite, $\mathrm{P}=$ phlogopite, $\mathrm{Q}=$ quartz

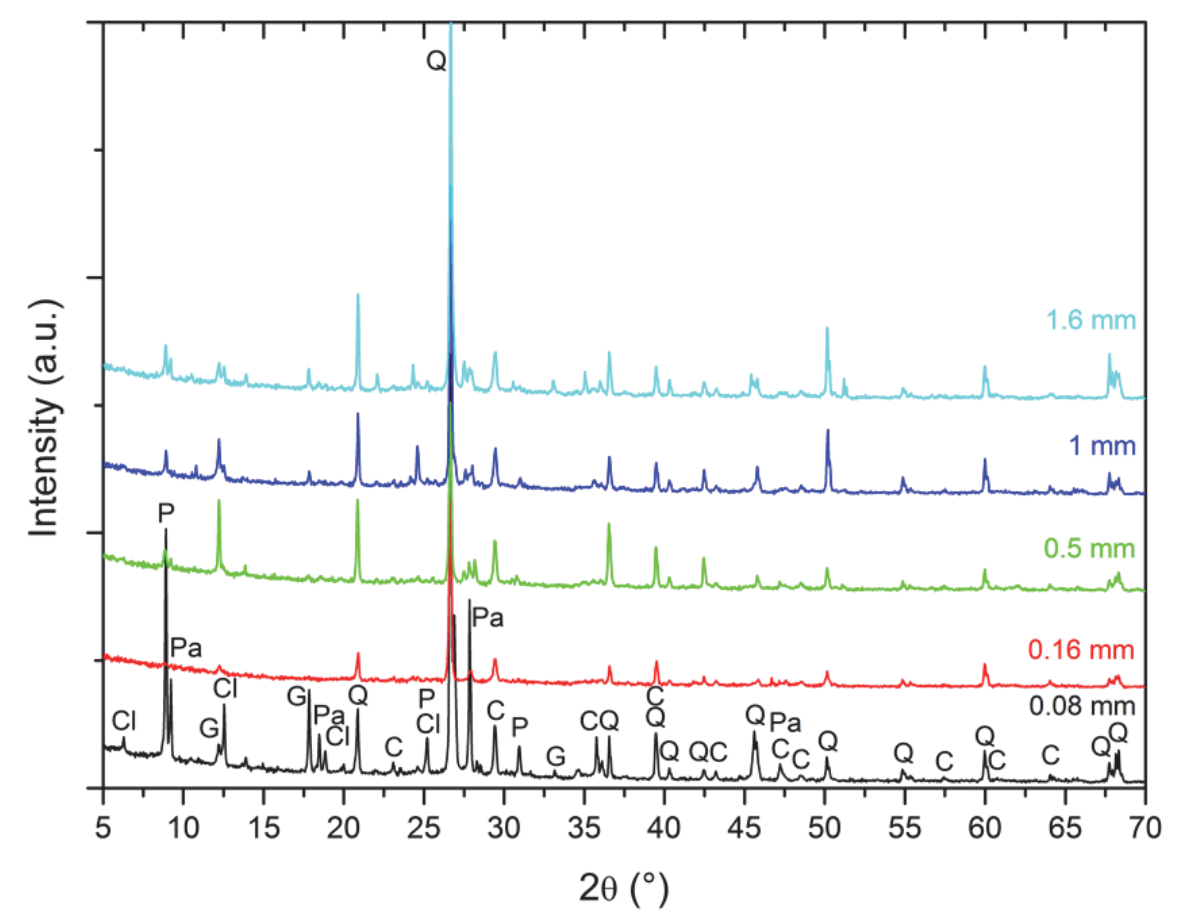

Figure 6: S Results of XRD analysis for all the retained fraction of Recycled Washed Sand.

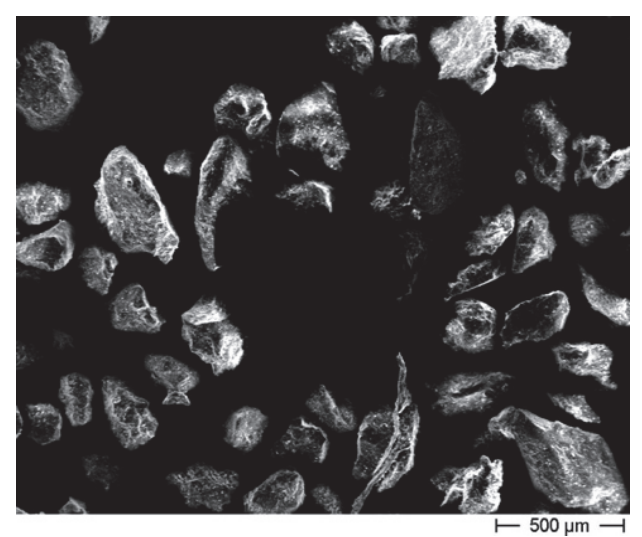

Figure 7: Particular of a grain of $0.16 \mathrm{~mm}$ of RSw.

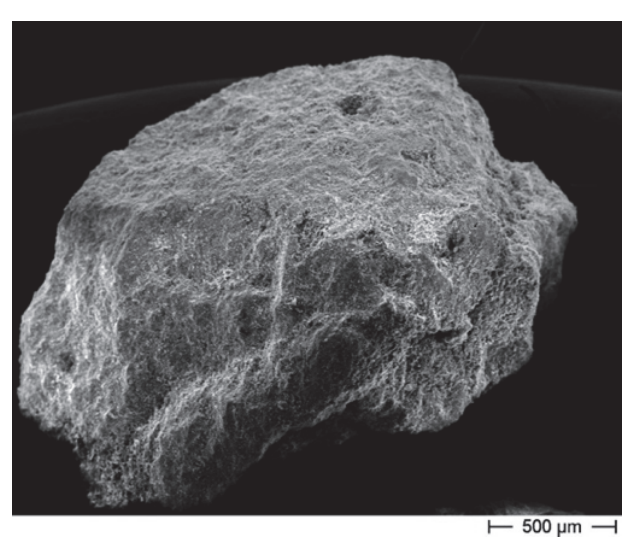

Figure 8: Particular of a grain of $1.00 \mathrm{~mm}$ of RSw. 
Results of mechanical tests

The mechanical experimental results showed very interesting indications, as sign that recycled washed sand RSw could be used as replacement of standard sand SS in mortar. The results of Series 1, Series 2 and Series 3 are reported in Tabs. 6-8. Each batch is composed of three specimens and the results correspond to the mean values \pm standard deviation.

\begin{tabular}{lcccccc}
\hline ID Batch & $\begin{array}{c}P_{M A X} \\
{[\mathrm{~N}]}\end{array}$ & $\begin{array}{c}E \\
{[\mathrm{GPa}]}\end{array}$ & $\begin{array}{c}K_{I C} \\
{[\mathrm{MPa} \sqrt{\mathrm{m}}]}\end{array}$ & $\begin{array}{c}G_{F} \\
{[\mathrm{~N} / \mathrm{m}]}\end{array}$ & $\begin{array}{c}\sigma_{f} \\
{[\mathrm{MPa}]}\end{array}$ & $\begin{array}{c}\sigma_{c} \\
{[\mathrm{MPa}]}\end{array}$ \\
\hline M-SS & $871.48 \pm 33.59$ & $5.72 \pm 0.71$ & $3.53 \pm 0.73$ & $5.62 \pm 8.91$ & $6.67 \pm 0.26$ & $59.16 \pm 0.79$ \\
& & & & & & \\
M-RSw_25\% & $529.31 \pm 20.77$ & $3.67 \pm 1.49$ & $3.05 \pm 1.20$ & $4.06 \pm 9.77$ & $4.05 \pm 0.16$ & $32.61 \pm 0.98$ \\
M-RSw_50\% & $685.54 \pm 24.99$ & $4.43 \pm 1.53$ & $3.90 \pm 1.31$ & $5.70 \pm 11.16$ & $5.25 \pm 0.19$ & $40.10 \pm 0.29$ \\
M-RSw_75\% & $820.71 \pm 75.25$ & $5.19 \pm 6.95$ & $3.66 \pm 3.58$ & $6.38 \pm 8.81$ & $6.28 \pm 0.58$ & $56.49 \pm 2.10$ \\
M-RSw_100\% & $871.41 \pm 13.33$ & $4.70 \pm 2.55$ & $4.05 \pm 3.97$ & $7.46 \pm 11.05$ & $6.67 \pm 0.10$ & $56.20 \pm 1.37$ \\
\hline
\end{tabular}

Table 6: Mechanical and fracture results, Series $1(\mathrm{w} / \mathrm{c}=0.5 ; 1.00 \% \mathrm{SP} 1)$.

\begin{tabular}{lcccccc}
\hline ID Batch & $\begin{array}{c}P_{M A X} \\
{[\mathrm{~N}]}\end{array}$ & $\begin{array}{c}E \\
{[\mathrm{GPa}]}\end{array}$ & $\begin{array}{c}K_{I C} \\
{[\mathrm{MPa} \sqrt{\mathrm{m}}]}\end{array}$ & $\begin{array}{c}G_{F} \\
{[\mathrm{~N} / \mathrm{m}]}\end{array}$ & $\begin{array}{c}\sigma_{f} \\
{[\mathrm{MPa}]}\end{array}$ & $\begin{array}{c}\sigma_{c} \\
{[\mathrm{MPa}]}\end{array}$ \\
\hline M-SS & $871.48 \pm 33.59$ & $5.72 \pm 0.73$ & $3.53 \pm 0.73$ & $5.62 \pm 8.91$ & $6.67 \pm 0.26$ & $59.16 \pm 0.79$ \\
& & & & & & \\
M-RSw_25\% & $551.81 \pm 33.85$ & $3.92 \pm 1.71$ & $3.25 \pm 1.72$ & $4.03 \pm 6.65$ & $4.22 \pm 0.26$ & $34.79 \pm 0.57$ \\
M-RSw_50\% & $611.54 \pm 15.72$ & $4.10 \pm 2.94$ & $3.54 \pm 7.57$ & $4.83 \pm 4.81$ & $4.68 \pm 0.12$ & $38.50 \pm 0.19$ \\
M-RSw_75\% & $684.99 \pm 49.19$ & $4.07 \pm 2.41$ & $3.68 \pm 1.92$ & $5.94 \pm 5.21$ & $5.24 \pm 0.32$ & $46.23 \pm 0.68$ \\
M-RSw_100\% & $816.37 \pm 22.20$ & $4.13 \pm 2.91$ & $4.06 \pm 1.22$ & $7.03 \pm 2.02$ & $6.25 \pm 0.17$ & $50.20 \pm 1.39$ \\
\hline
\end{tabular}

Table 7: Mechanical and fracture results, Series $2(\mathrm{w} / \mathrm{c}=0.5 ; 0.75 \% \mathrm{SP} 1)$.

\begin{tabular}{lcccccc}
\hline ID Batch & $\begin{array}{c}P_{\text {MAX }} \\
{[\mathrm{N}]}\end{array}$ & $\begin{array}{c}E \\
{[\mathrm{GPa}]}\end{array}$ & $\begin{array}{c}K_{I C} \\
{[\mathrm{MPa} \sqrt{\mathrm{m}}]}\end{array}$ & $\begin{array}{c}G_{F} \\
{[\mathrm{~N} / \mathrm{m}]}\end{array}$ & $\begin{array}{c}\sigma_{f} \\
{[\mathrm{MPa}]}\end{array}$ & $\begin{array}{c}\sigma_{c} \\
{[\mathrm{MPa}]}\end{array}$ \\
\hline M-SS & $895.79 \pm 50.21$ & $6.46 \pm 2.08$ & $3.77 \pm 1.59$ & $7.32 \pm 3.05$ & $6.86 \pm 0.38$ & $55.00 \pm 2.19$ \\
& & & & & & \\
M-RSw_25\% & $653.00 \pm 15.98$ & $4.52 \pm 1.63$ & $3.73 \pm 1.31$ & $5.02 \pm 2.69$ & $5.00 \pm 0.12$ & $38.14 \pm 0.43$ \\
M-RSw_50\% & $685.83 \pm 15.00$ & $4.25 \pm 1.44$ & $3.99 \pm 1.40$ & $5.77 \pm 5.34$ & $5.25 \pm 0.11$ & $38.33 \pm 0.50$ \\
M-RSw_75\% & $881.68 \pm 62.57$ & $5.02 \pm 1.86$ & $4.31 \pm 3.41$ & $7.12 \pm 1.23$ & $6.75 \pm 0.48$ & $55.98 \pm 0.88$ \\
M-RSw_100\% & $893.78 \pm 30.17$ & $4.84 \pm 3.41$ & $4.22 \pm 1.91$ & $7.58 \pm 4.79$ & $6.84 \pm 0.23$ & $56.31 \pm 2.97$ \\
\hline
\end{tabular}

Table 8: Mechanical and fracture results, Series $3(\mathrm{w} / \mathrm{c}=0.45 ; 1.00 \% \mathrm{SP} 1)$.

According to Tabs. 6-8, it is evident that the greater is the percentage of $\mathrm{RSw}$ in mortars, the greater are mechanical performances, with very similar values to those of traditional ones.

This can be explained by the FESEM results: the particles of RSw appear highly irregular and indented, while those of standard sand by definition "are generally isometric and rounded in shape" [29]. Therefore, in compositions with higher percentages of $\mathrm{RSw}$, it is possible to hypothesize more non-homogeneity grains, which surely increase the ability to create a strong bond with the matrix. Furthermore, the washing process allows removing the fine powders $(<0.08 \mathrm{~mm})$ and 
impurities, reducing the higher absorption rate of recycled sand that influences workability of fresh state and mechanical properties of hardened state [30].

The second observation is that decreasing the amount of superplasticizer (Series 2), the results undergo a decrease for all the percentages. In fact, with the SP1 percentage of $0.75 \%$ there is a great decrease in terms of mechanical results between the Series 1 and the Series 2: this indicates that, fixed the w/c ratio, the correct amount of superplasticizer to use is equal to $1 \%$. The drop both in mechanical and fracture parameters can be related to the lack of cement grain and recycled washed sand dispersion because of the fewer amount of SP1.

By the Series 3 analysis, it is not surprising to find an improvement for all the compositions: the superplasticizer was brought back to optimum condition $(1 \%)$ and the $\mathrm{w} / \mathrm{c}$ ratio has been decreased (from 0.50 to 0.45 ), which have great influence on workability and hardened properties of mortars [31]. In Figs. 9-11 are reported the Load-CMOD curves, obtained by TPB tests for mortars with SS and mortars with RSw, for each series considered. From the observation of experimental curves, it is possible to note that mortars with recycled sand percentage replacement above $75 \%$ behave in a "more ductile" manner with respect to the standard mortar. This can be attributed to the presence of the superplasticizer, which counterbalances the detrimental effects associated with the use of recycled sand in compositions. As found in literature, if superplasticizer is used to reduce the w/c ratio, the fine recycled fraction can be as good as the conventional type [32]. For this reason, in Series $3(\mathrm{w} / \mathrm{c}=0.45 ; 1.00 \% \mathrm{SP} 1)$, the best results can be found. Moreover, the improvement in ductility at $75 \% \mathrm{RSw}$ might be linked to the increase in elongated grains of recycled sand replacing the more spherical standard sand grains in cementitious matrix.

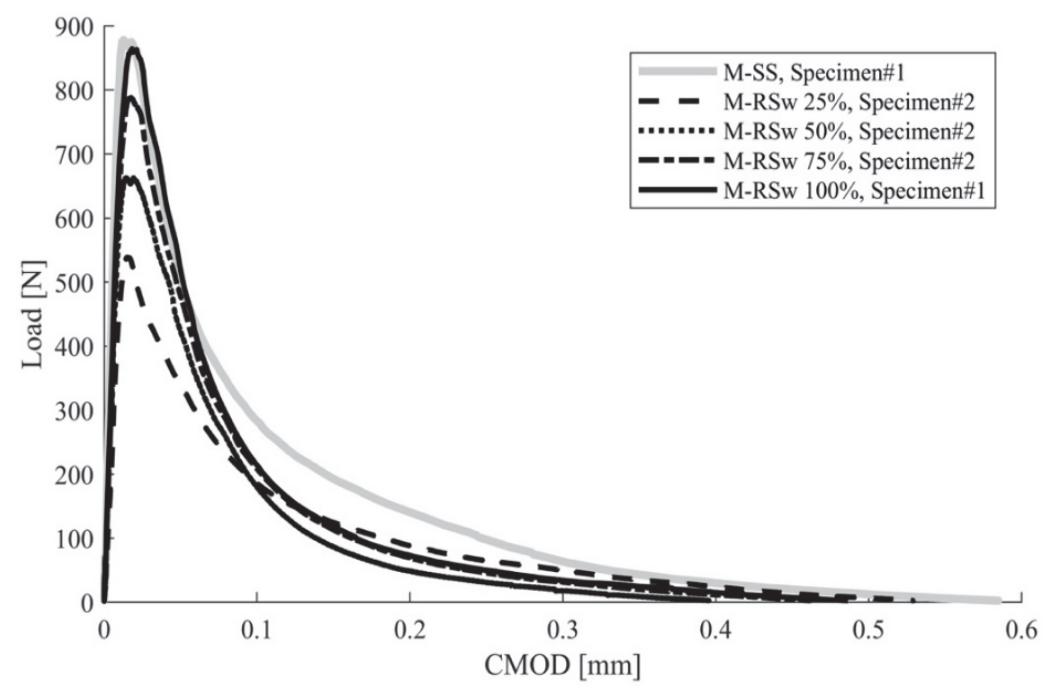

Figure 9: Load-CMOD curves, series 1.

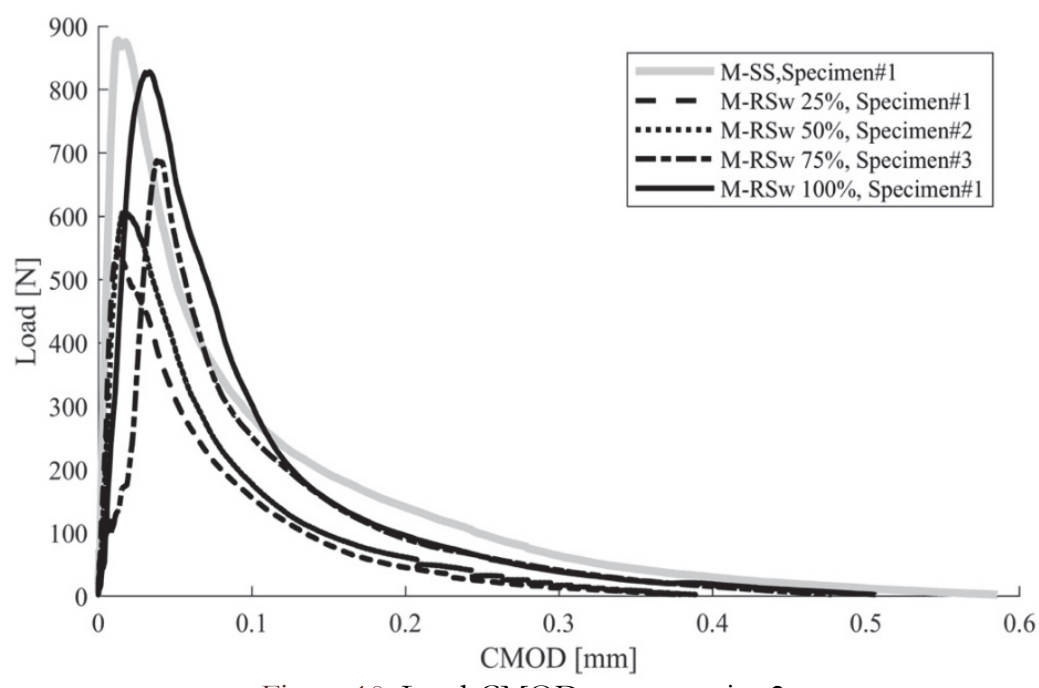

Figure 10: Load-CMOD curves, series 2. 


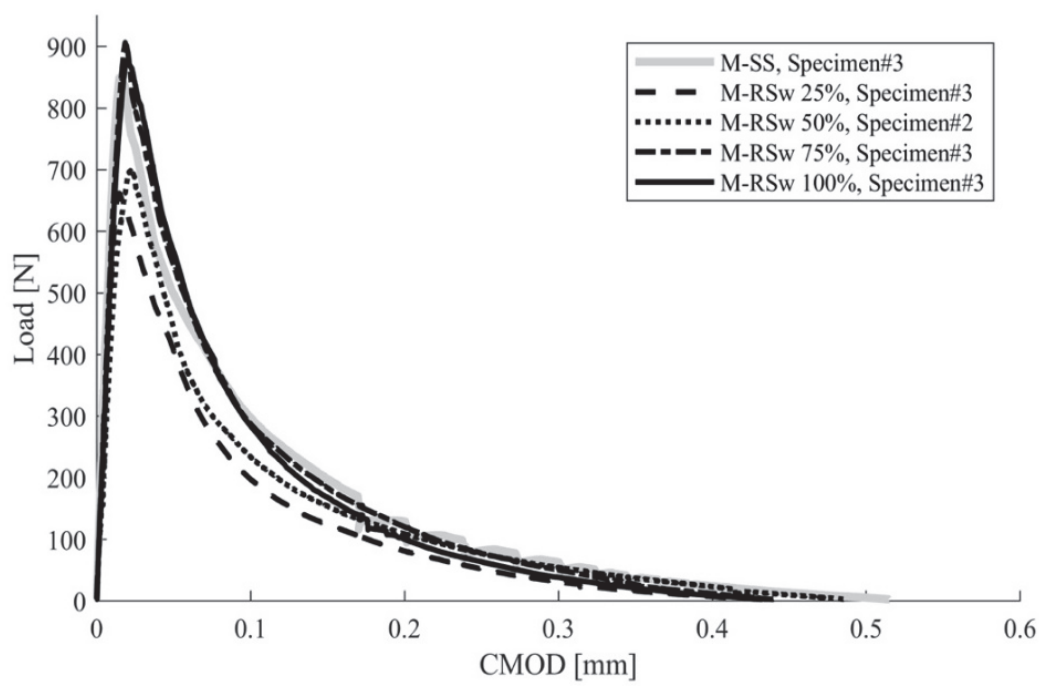

Figure 11: Load-CMOD curves, series 3.

To produce completely recycled materials, Series 4 has been done only for mortar with standard sand (M-SS) and for mortar with $100 \%$ of recycled sand (M-RSw 100\%). In this case, the amount of SP1 has been maintained at 1\% dose, while the w/c ratio has been lowered.

In Tab. 9 the results concerning the mechanical tests are reported. The improvement trend follows that of the previous series, as a sign that the increased presence of recycled sand grains can ensure a strong bond with the matrix: this might explain, in fact, the substantial increase in terms of fracture energy $G_{F}$.

\begin{tabular}{|c|c|c|c|c|c|c|}
\hline ID Batch & $\begin{array}{c}P_{M A X} \\
{[\mathrm{~N}]}\end{array}$ & $\begin{array}{c}E \\
{[\mathrm{GPa}]}\end{array}$ & $\begin{array}{c}K_{I C} \\
{[\mathrm{MPa} \sqrt{\mathrm{m}}]}\end{array}$ & $\begin{array}{c}G_{F} \\
{[\mathrm{~N} / \mathrm{m}]}\end{array}$ & $\begin{array}{c}\sigma_{f} \\
{[\mathrm{MPa}]}\end{array}$ & $\begin{array}{c}\sigma_{c} \\
{[\mathrm{MPa}]}\end{array}$ \\
\hline M-SS & $1021.14 \pm 53.22$ & $6.02 \pm 3.98$ & $4.79 \pm 3.52$ & $6.40 \pm 3.41$ & $7.81 \pm 0.41$ & $45.88 \pm 2.30$ \\
\hline M-RSw_100\% & $909.10 \pm 65.64$ & $4.71 \pm 1.21$ & $4.38 \pm 1.45$ & $8.65 \pm 6.73$ & $6.96 \pm 0.50$ & $52.68 \pm 5.08$ \\
\hline
\end{tabular}

Table 9: Mechanical and fracture results, Series 4 (w/c $=0.40 ; 1.00 \% \mathrm{SP} 1)$.

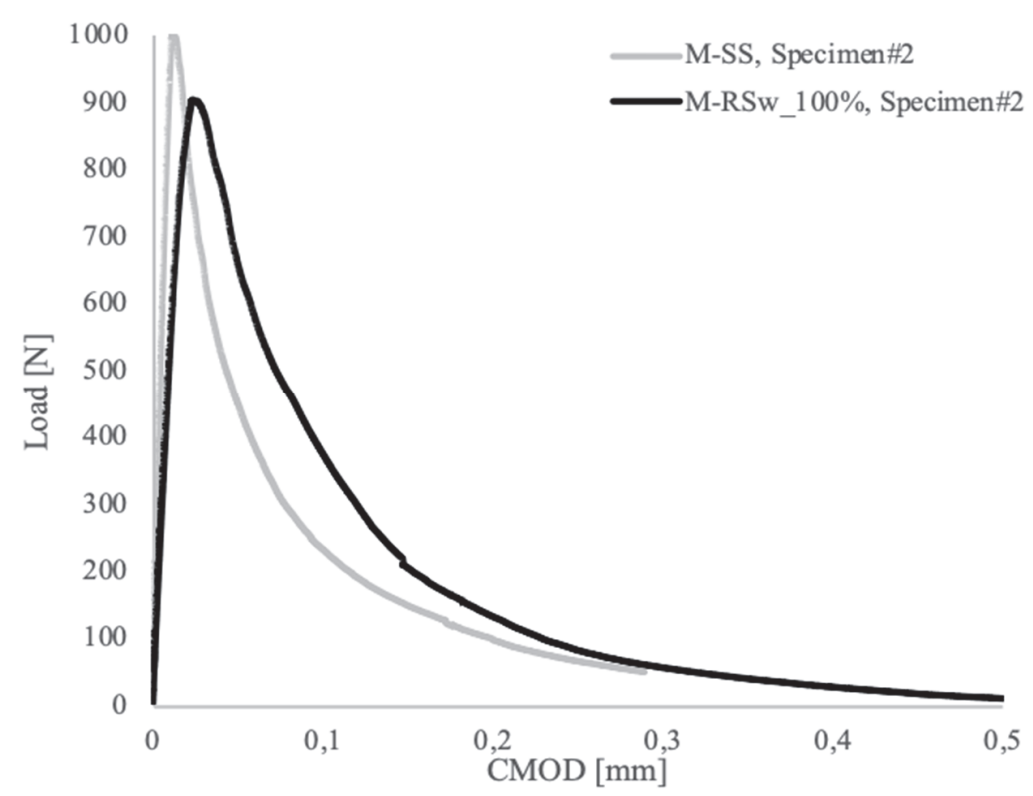

Figure 12: Load-CMOD curves, series 4. 
In Fig. 12, the curve Load-CMOD for two experimental specimens of the Series 4 is shown, through which it is possible to explain the enhancement of fracture energy, by evaluating the ductility factor $\mu$. Ductility factor is defined as the ratio between the ultimate displacement $\delta_{\mathrm{u}}$ and displacement corresponding to the peak load $\delta_{\mathrm{p}}$ :

$$
\mu=\delta \mathrm{u} / \delta \mathrm{P}
$$

and, in this case, it is equal to 1.92 for M-SS (Specimen\#2) and 2.47 for M-RSw_100\% (Specimen\#2). Analysing the values of Young's modulus E reported in Tab. 9 and observing Fig. 12, a little change of slope of the first portion of the LoadCMOD curves can be seen. In literature, the lowest Young's modulus is attributed to the residues adhered of recycled aggregates [33], but probably in this case there is still a correlation with the amount of superplasticizer used. In fact, in the traditional mortar $4.5 \mathrm{~g}$ of SP1 have been used while $13.5 \mathrm{~g}$ in the mortar with $100 \% \mathrm{RSw}$ (as reported in Tab. 3). This lead to a difference in density of the two mixtures, which may explain the small decrease in the elastic modulus, according to Mehta and Monteiro [34].

\section{CONCLUSIONS}

I $\mathrm{n}$ this research work, an investigation regarding the feasibility of replacing in traditional mortars the fine fraction of CDW waste has been conducted. This topic has still little relevance in scientific literature, as it is believed that the greater water absorption of recycled sand could compromise mechanical properties of both fresh and hardened states. The importance of this research lies in the fact that, through the washing process, it is possible to obtain suitable sand to be re-used in building materials. Mechanical and fracture properties of mortars with RSw are extremely similar to those of traditional mortars, even exhibiting an improvement regarding fracture toughness and fracture energy.

Based on the test results, the main conclusions are as follows:

- the higher the percentage of Recycled washed sand in mortars, the higher mechanical performances. This is probably related to a huge presence of irregular and indented grains of recycled sand, which ensure a more cohesive bond with cement matrix;

- the presence of the superplasticizer counterbalances the detrimental effects associated with the use of recycled sand. Their joint use is a solution to offset the negative effects caused by recycled sand incorporation [19] and, if superplasticizer has being varied with respect to the weight of recycled sand for each composition, then the workability is ensured; this is a critical parameter for the performance of fresh and hardened states;

- it is possible to evaluate not only the fineness of the recycled sand used in correlation with water requirement, but also the quality of the superplasticizer as parameters for the mix-design of the mixture [19-21].

- although specific studies are required in order to obtain an optimal mix-design of mortars made with fine recycled sand, it can be stated that it is technically feasible to use it for mortar production, especially when powder of $<0.08$ $\mathrm{mm}$ fraction is eliminated.

\section{AbBreviations}

SS, standard sand;

RS, recycled sand;

SP, superplasticizer;

RSw, recycled washed sand,

CDW, construction and demolition waste;

M-SS, mortar with standard sand;

M-RSw, mortar with recycled washed sand;

ITZ, Interfacial Transition Zone.

\section{REFERENCES}

[1] Steinberger, J.K., Krausmann, F. and Eisenmenger, N. (2010). Global patterns of materials use: a socioeconomic and geophysical analysis, Ecological Economics 69, pp. 1148-1158. DOI: 10.1016/j.ecolecon.2009.12.009. 
[2] USGS (2013). Cement, statistics and information. U.S. Geological Survey, Reston.

[3] Gameiro, F., de Brito, J. and Correia da Silva, D. (2014). Durability performance of structural concrete containing fine aggregates from waste generated by marble quarrying industry, Eng Struct 59, pp. 654-662. DOI: $10.1016 /$ j.engstruct.2013.11.026.

[4] Galetakis, M., Piperidi, C., Vasiliou, A., Alevizos, G., Steiakakis, E., Komnitsas K. and Soultana, A. (2016). Experimental investigation of the utilization of quarry dust for the production of microcement-based building elements by self-flowing molding casting, Constr Build Mater 107, pp. 247-254. DOI: 10.1016/j.conbuildmat.2016.01.014.

[5] Schankoski, R.A., Pilar, R., Prudêncio Jr., L.R. and Douglas Ferron, R. (2017). Evaluation of fresh cement pastes containing quarry by-product powders, Constr Build Mater 133, pp. 234-242. DOI: 10.1016/j.conbuildmat.2016.12.056.

[6] Bilir, T., Gencel, O. and Topcu, I. B. (2015). Properties of mortars with fly ash as fine aggregate, Constr Build Mater 93, pp. 782-789. DOI: 10.1016/j.conbuildmat.2015.05.095.

[7] Thomas, J. and Harilal, B. (2015). Properties of cold bonded quarry dust coarse aggregates and its use in concrete, Cem Concr Compos 62, pp. 67-75. DOI: 10.1016/j.cemconcomp.2015.05.005.

[8] CEDR (2012). Recycling: Road construction in a post-fossil fuel society, Transnational Road Research Programme Call;

[9] Westerholm, M., Lagerblad, B., Silfwerbrand, J. and Forssberg, E. (2008). Influence of fine aggregate characteristics on the rheological properties of mortars, Cem Concr Compos 30, pp. 274-282. DOI: 10.1016/j.cemconcomp.2007.08.008.

[10] Katz, A. and Baum, H. (2006). Effect of high levels of fines content on concrete properties, ACI Mater J 103, pp. 474482.

[11] Dapena, E., Alaejos, P., Lobet, A. and Pérez, D. (2010). Effect of recycled sand content on characteristics of mortars and concretes, J Mater Civil Eng 23, pp. 414-422. DOI: 10.1061/(ASCE)MT.1943-5533.0000183.

[12] Braga, M., de Brito, J. and Veiga, R. (2012). Incorporation of fine concrete aggregates in mortars, Constr Build Mater 36, pp. 960-968. DOI: 10.1016/j.conbuildmat.2012.06.031.

[13] Zhao, Z., Remond, S., Damidot, D. and Xu, W. (2015). Influence of fine recycled concrete aggregates on the properties of mortars, Constr Build Mater 81, pp. 179-186. DOI: 10.1016/j.conbuildmat.2015.02.037.

[14] Lahuerta, J.V. and Monterde, G.J.C. (2012). Estudio teorico y experimental sobre los morteros para muros resistentes de fabrica de ladrilho para la actualizacion de la Norma Basica MV 201-1972; 1 parte: memoria del estudio. Materiales de Construccion 34, pp. 33-41. DOI: 10.3989/mc.1984.v34.i196.936.

[15] Le, T., Rémond, S., Le Saout, G. and Garcia-Diaz, E. (2016). Fresh behavior of mortar based on recycled sand Influence of moisture condition, Constr Build Mater 106, pp. 35-42. DOI: 10.1016/j.conbuildmat.2015.12.071.

[16] Li, L., Zhan, B. J., Lu, J. and Sun Poon, C. (2019). Systematic evaluation of the effect of replacing river sand by different

[17] particle size ranges of fine recycled concrete aggregates (FRCA) in cement mortars, Constr Build Mater 209, pp. 147155. DOI: $10.1016 /$ j.conbuildmat.2019.03.044.

[18] Pacheco, J., de Brito, J., Ferreira, J. and Soares, D. (2015). Destructive horizontal load tests of full-scale recycled aggregate concrete structures, ACI Struct. J. 112 (6), pp. 815-826. DOI: 10.14359/51687800.

[19] Miranda, L. and Selmo, S. (2006). CDW recycled aggregate renderings: Part I - Analysis of the effect of materials finer than $75 \mu \mathrm{m}$ on mortar properties, Constr Build Mater 20, pp. 615-624. DOI: 10.1016/j.conbuildmat.2005.02.025.

[20] Bravo, M., de Brito, J., Evangelista, L. and Pacheco, J. (2017). Superplasticizer's efficiency on the mechanical properties of recycled aggregates concrete: Influence of recycled aggregates composition and incorporation ratio, Constr Build Mater 153, pp. 129-138. DOI: 10.1016/j.conbuildmat.2017.07.103.

[21] Cartuxo, F., de Brito, J., Evangelista, L., Jiménez, J.R. and Ledesma, E.F. (2015). Rheological behaviour of concrete made with fine recycled concrete aggregates - Influence of the superplasticizer, Constr Build Mater 89, pp. 36-47. DOI: $10.1016 /$ j.conbuildmat.2015.03.119.

[22] Li, J. and Yang, E-H. (2017). Macroscopic and microstructural properties of engineered cementitious composites incorporating recycled concrete fines, Cem Concr Compos 78, pp. 33-42. DOI: 10.1016/j.cemconcomp.2016.12.013.

[23] Vinay Kumar, B.M., Ananthan, H. and Balaji, K.V.A. (2017). Experimental studies on utilization of coarse and finer fractions of recycled concrete aggregates in self-compacting concrete mixes, Journal of Building Engineering 9, pp. 100-108. DOI: 10.1016/j.jobe.2016.11.013.

[24] Ferro, G.A, Spoto, C., Tulliani, J.M. and Restuccia, L. (2015). Mortars made of recycled sand from C\&D, Procedia Engineering 109, pp. 240 - 247. DOI: 10.1016/j.proeng.2015.06.224.

[25] Restuccia, L., Spoto, C., Ferro, G.A. and Tulliani, J.M. (2016). Recycled Mortars with C\&D Waste, Procedia Structural Integrity 2, pp. 2896-2904. DOI: 10.1016/j.prostr.2016.06.362.

[26] Bažant, Z.P. and Oh, B.H. (1983). Crack Band Theory for Fracture Concrete, Mater. Struct 16, pp. $155-177$. DOI: $10.1007 / \mathrm{BF} 02486267$.

[27] Jenk, Y. and Shah, S.P. (1985). Two parameter fracture model for concrete, J. Eng. Mech. 111, pp. $1227-1241$. 
[28] Shah, S.P. (1990). RILEM TC 89-FMT, Determination of fracture parameters (KIC and CTODc) of plain concrete using three-point bend tests, Mater. Struct. 23, pp. 457-460.

[29] RILEM TCS (1985). Determination of the fracture energy of mortar and concrete by means of three-point bend tests on notched beams, Mater. Struct. 18, pp. 285-290.

[30] CEN STANDARD SAND EN 196-1: 2005 (ISO STANDARD SAND ISO 679: 2009).

[31] Evangelista, L. and de Brito, J. (2014). Concrete with fine recycled aggregates: a review. Eur J Environ Civ Eng 18, pp. 129-172. DOI: 10.1080/19648189.2013.851038

[32] Haach, V.G., Vasconcelos, G. and Lourenço, P.B. (2011). Influence of aggregates grading and water/cement ratio in workability and hardened properties of mortars, Constr Build Mater 25, pp. 2980-2987. DOI: 10.1016/j.conbuildmat.2010.11.011.

[33] Pereira, P., Evangelista, L. and de Brito, J. (2012). The effect of superplasticisers on the workability and compressive strength of concrete made with fine recycled concrete aggregates, Constr Build Mater 28, pp. 722-729. DOI: 10.1016/j.conbuildmat.2011.10.050.

[34] Hansen, T. (1992). Recycling of demolished concrete and masonry, RILEM report 6, London, UK: E\&FN Spon. DOI: $10.1201 / 9781482267075$.

[35] Mehta, P.K. and Monteiro, P.J.M. (2006). Concrete: microstructure properties and materials, 3rd ed. McGraw Hill. 